Research article

\title{
Curiosity for information predicts well-being during COVID-19 Pandemic: Contributions of loneliness and daily lifestyle
}

Losecaat Vermeer, A.B. ${ }^{1,2}$, Muth, A. ${ }^{1,2}$, Terenzi, D. ${ }^{1,2,3}$, Park, S.Q. ${ }^{1,2,3} *$

${ }^{1}$ Department of Decision Neuroscience and Nutrition, German Institute of Human Nutrition Potsdam-Rehbrücke, Germany

${ }^{2}$ Charité-Universitätsmedizin Berlin, Corporate member of Freie Universität Berlin, HumboldtUniversität zu Berlin, Berlin, Germany

${ }^{3}$ Deutsches Zentrum für Diabetes, Neuherberg, Germany

${ }^{*}$ ) correspondence to: annabel.losecaat_vermeer@dife.de; soyoung.q.park@gmail.com

Disclaimer: This paper has not been peer reviewed yet (23.08.2021) 


\section{Abstract}

1 The COVID-19 pandemic confronted humans with high uncertainty and lockdowns, which severely

2 disrupted people's daily social and health lifestyles, enhanced loneliness and reduced well-being.

3 Curiosity and information-seeking are central to behavior, fostering well-being and adaptation in

4 changing environments. They may be particularly important to maintain well-being during the

5 pandemic. Here, we investigated which motives drive information-seeking, and whether and how

6 curiosity and information-seeking related to well-being and mood (excitement, anxiety).

7 Additionally, we tested whether daily diet contributed to this relationship during lockdown.

8 Participants $(N=183)$ completed questionnaires measuring curiosity, information-seeking, social and

9 mental health. Using a smartphone app, participants submitted their daily food intake and lifestyle

10 ratings for a week. We found participants had highest motivation to seek positive (vs. negative)

11 information, concerning themselves more than others. Both trait curiosity and information-seeking

12 predicted higher well-being, by reduced loneliness. Trait curiosity also predicted well-being and

13 excitement days later. Considering diet, people with lower curiosity consumed food high in

14 dopamine precursor tyrosine, whereas high-sugar intake increased anxiety, only in people with

15 relatively low, but not high, trait curiosity. Taken together, curiosity and information-seeking may

16 benefit well-being and mood in high uncertain and challenging times, by interacting with lifestyle

17 measures (loneliness and nutrition).

20 Keywords: Curiosity; information-seeking; well-being; loneliness; diet; COVID-19 
Introduction

The 2020 COVID-19 pandemic has confronted humans with high uncertainty and severely disrupted human societal daily life. Strict lockdowns induced a dramatic decrease in individual well-being, lifestyle changes including diet, and significantly reduced social interactions resulting in increased loneliness and stress ${ }^{1,2}$. Alongside these effects and the acute threat of the virus, the constant and unlimited information shared through news outlets and social media exposed individuals to vast amounts of information - accurate and inaccurate - not only regarding the coronavirus, but also restrictions to daily lives ${ }^{3}$. Although information can aid decisions to obtain reward and avoid harm, individuals are generally motivated to avoid news they expect to have a negative impact on their feelings ${ }^{4,5}$. The abundance of COVID-19-related information likely enhanced uncertainty and feelings of anxiety, negatively impacting well-being ${ }^{3}$. Yet, how much knowledge is wanted in times of high uncertainty and loneliness, and how it relates to one's well-being is unclear. A better understanding of these relationships during the pandemic is crucial for developing appropriate policies to provide adequate information and protect individuals from loneliness and poor mental health in the future.

Trait curiosity is commonly defined as the intrinsic desire for knowledge and seeking out novel, challenging situations ${ }^{6}$. This feeling, often compared to the feeling of hunger or thirst, is expressed in information-seeking behaviors such as reading, asking questions, conducting searches online, and watching the news. Both trait curiosity and its behavioral expression are fundamental for motivation, learning, and achieving and maintaining well-being ${ }^{7-9}$. For instance, trait curiosity is positively associated with life satisfaction and well-being ${ }^{10}$ and better coping with unfamiliar, uncertain information and challenging interactions ${ }^{8}$. Curiosity may facilitate such behaviors and promote well-being through positive emotions and reducing uncertainty. According to the broadenand-build framework ${ }^{11}$, positive emotions broadens people's scope of attention and thinking, promote exploration and engagement with their environment to build knowledge, and regulate 
negative emotions, thereby reducing uncertainty and enhancing psychological resiliency. Hence, being curious and gathering information can be beneficial for coping with challenging situations. Moreover, what information people want to know (e.g., positive or negative) may reflect their mental state and mood ${ }^{4}$. Despite curiosity and information-seeking being integral to behavior, we know little about how it relates to well-being in an extensive period of social restrictions during an acute global health crisis.

Social interaction is critical for mental well-being ${ }^{12}$. In novel situations, we may be more eager to seek information from others (e.g., through observation) than by ourselves to minimize harm and avoid risk ${ }^{13,14}$, possibly demonstrating a self-other disctinction in information-seeking. The imposed social restrictions reportedly increased loneliness by $20-30 \%$ during the pandemic, being highest during the first European lockdown in Spring 2020. Even later into the COVID-19 restrictions (i.e. late November 2020), $24 \%$ of 4436 adults partaking in a UK survey of the Mental Health Foundation (www.mentalhealth.org.uk) reported feeling lonely. Loneliness refers to the subjective feeling or perceived social isolation, and predicts negative life outcomes related to physical and mental wellbeing, including depression and anxiety ${ }^{15,16}$. However, not all individuals of this survey had been experiencing loneliness Interestingly, loneliness has been associated with stable personality traits such as extraversion and openness ${ }^{17,18}$. Yet, it is unknown whether such relation exists for trait curiosity, and if so, whether loneliness plays a mediating role in the relation between curiosity and mental well-being. Besides social impact, lockdowns also affect our daily lifestyle ${ }^{1}$. Daily lifestyles including diet are hypothesized to significantly impact mental well-being. In particular, fruits and vegetables, and large amino acids including tyrosine and tryptophan predict outcomes such as positive mood, better

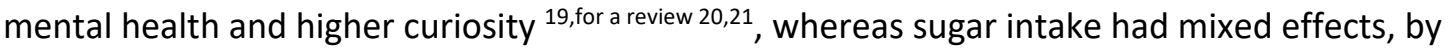
predicting lower well-being but more curiosity ${ }^{19}$. Tyrosine and tryptophan are essential precursors 
of neurotransmitters dopamine and serotonin, important for motivation and mood, respectively ${ }^{22,23}$. For instance, acute tyrosine and tryptophan depletions cause impairments in reward processing (e.g. reduced motivation for rewards) and lower mood ${ }^{24,25}$. Furthermore, studies have implicated a key role for dopamine in motivating information-seeking and exploration, as shown by the dopamine reward circuitry signalling the value of information $4,26,27$, and the relief of curiosity ${ }^{28}$. Based on these findings, changes in tyrosine and tryptophan from the food we eat may influence curiosity and information-seeking motivation, and thereby influencing our affective mental state. Simultaneously, lockdown-induced stress and loneliness may alter diet by preferring high-fat and high-carb food, as suggested by stress studies in animals ${ }^{29}$ and humans ${ }^{30}$, and thus negatively impact curiosity and well-being. A question we aimed to explore is whether there is any link between curiosity, both trait and behavior, with daily intake of macronutrients and amino acids during the lockdown, to predict well-being and mood.

In this preregistered study, we first investigated whether individuals are motivated to seek particular information specific for themselves and about others in an uncertain time involving increased Ioneliness, namely during the pandemic lockdown. Second, we examined how individual's curiosity relate to mental well-being and mood. We assessed both individual's trait curiosity level and their information-seeking motivation as an expression of curiosity. We hypothesized that trait curiosity is associated with individual's mental well-being and mood (i.e. positive and negative mood). Third, based on previous studies reviewed here, we explored if relationships between curiosity with wellbeing and with mood are dependent on dietary intake during lockdown. To test these hypotheses, we conducted an online study in adults living in Germany and Austria $(N=183)$ during a national lockdown in the period from 10 November - 23 December 2020. Participants completed questionnaires assessing trait curiosity, information-seeking, loneliness, mental health, and COVID19-related impact (e.g., work situation, regulation compliance). Afterwards, participants submitted their self-rated levels of mood, well-being, and food intake for 7 days during lockdown. 
100 Hundred eighty-seven participants signed up via Prolific for one of two preregistered online studies

101 (i.e. one for Germany and one for Austria, see Methods). We excluded four participants with self-

102 reported severe depression symptoms (i.e. Beck Depression Inventory score $>30$, see Methods),

103 resulting in 183 participants who completed the questionnaire battery. Of those participants, a total

104 of 172 participants submitted their daily food intake and mood ratings for at least two days using the

105 food-diary app. Therefore, analysis on daily mood and food observations were performed on these

106172 participants. In Table 1, we provide descriptive statistics.

107

108 Table 1. Descriptive statistics

\begin{tabular}{|c|c|c|}
\hline Characteristic & $\begin{array}{l}\text { Total sample } \\
(\mathrm{N}=183)^{1}\end{array}$ & $\begin{array}{l}\text { Sample with diary data } \\
(\mathrm{n}=172)^{1^{*}}\end{array}$ \\
\hline Age & $28.51(8.94)$ & $28.52(8.98)$ \\
\hline BMI & $23.91(4.44)$ & $23.93(4.06)$ \\
\hline \multicolumn{3}{|l|}{ Gender } \\
\hline female & 74 / 183 (40\%) & 69 / 172 (40\%) \\
\hline male & 109 / $183(60 \%)$ & $103 / 172(60 \%)$ \\
\hline \multicolumn{3}{|l|}{ Nationality } \\
\hline Austrian & 37 / 183 (20\%) & 34 / 172 (20\%) \\
\hline German & $130 / 183(71 \%)$ & $128 / 172(74 \%)$ \\
\hline Other & $16 / 183(8.7 \%)$ & 10 / 172 (5.8\%) \\
\hline \multicolumn{3}{|l|}{ Country of residence } \\
\hline Austria & 54 / 183 (30\%) & $46 / 172$ (27\%) \\
\hline Germany & 129 / $183(70 \%)$ & $126 / 172(73 \%)$ \\
\hline COVID-19 rules compliance (0-100) & 82.33 (19.71) & $81.70(19.97)$ \\
\hline $\begin{array}{l}{ }^{1} \text { Mean (SD); } \boldsymbol{n} / \boldsymbol{N}(\%) \\
{ }^{*} \text { minimum of } 2 \text { diary submissions }\end{array}$ & & \\
\hline
\end{tabular}

109

110

111 


\begin{tabular}{|c|c|}
\hline $\begin{array}{l}\text { Day 1: Questionnaires } \\
\qquad(N=183)\end{array}$ & $\begin{array}{l}\text { Daily diary: lifestyle and mood (max. } 7 \text { days, } \\
\text { FoodApp, } N=172 \text { ) }\end{array}$ \\
\hline $\begin{array}{l}\text { Curiosity } \\
\text { - Trait curiosity } \\
\text { - Information-seeking } \\
\text { motivation }\end{array}$ & $\begin{array}{l}\text { Food intake } \\
\text { Food and beverages for each type of meal (breakfast, lunch, } \\
\text { dinner, snack) }\end{array}$ \\
\hline $\begin{array}{l}\text { Mental health \& well-being } \\
\text { - Well-being (baseline, WEMWBS) } \\
\text { - } \quad \text { Loneliness } \\
\text { - } \\
\text { - } \quad \text { Perceivety (trait) } \\
\text { - } \quad \text { Depressive symptoms }\end{array}$ & $\begin{array}{l}\text { Well-being / mood / lifestyle measures } \\
\text { - Well-being (short WEMWBS) } \\
\text { - } \quad \text { Anxiety (how anxious do you feel?) } \\
\text { - } \quad \text { Excitement (how excited do you feel?) } \\
\text { - } \quad \text { Lifestyle factors (e.g. activity, sleep) }\end{array}$ \\
\hline
\end{tabular}

113 Figure 1. Outline of the study. On the first testday, participants completed personality questionnaires 114 measuring curiosity, mental well-being, demographics among others (see Methods). Subsequently, using 115 the food-diary app, participants submitted their daily food intake for a week, and their ratings on well116 being, mood and other lifestyle factors once a day.

\section{Drivers of information-seeking}

119 Curiosity and information-seeking behavior can be driven by distinct motives. Generally, people are

120 motivated to seek information they expect to have positive impact on their feelings (valence-

121 dependent), and avoid information that may have negative impact on their feelings or mood ${ }^{4,5}$. In

122 addition, we do not only acquire information on our own experiences, but also information directed towards and from others ${ }^{31}$.

We first examined how individuals' information-seeking behavior is driven by the valance (i.e. potential positive or negative information) and target of information (i.e. about ourselves or others).

127 To test this, we asked participants how motivated they were at the present time to actively seek

128 information (e.g. through searching the web, reading, asking questions) that was; 1 ) expected to be 129 positive or negative, and 2) for themselves and about others. Participants rated their motivation on 130 a slider from 0-100 (with 0 not motivated at all, 100 being highly motivated). This provided four 131 ratings that allowed us to test potential drivers predicting information-seeking motivation, by 132 performing a mixed effects model. This model contained within-subject predictors for the valence 
133 (positive, negative) and the information target (self, other) and their interaction. Furthermore, we

134 included random slopes and participants as random intercept.

135

136 Overall, participants were motivated to seek information $(M=66.22, p<.001$, against 50 at which

137 participants are neither motivated nor demotivated). Moreover, participants were more motivated

138 to seek positive rather than negative information (i.e. valence-dependent, beta $=7.81, t(182)=8.16$,

$139 p<.001$ ), and information for oneself rather than others (i.e. information target, beta $=3.17, t(182)=$

$1404.49, p<.001)$. Importantly, there was a significant valence by information-target interaction (beta $=$

$141-1.11, t(182)=-2.10, p=.036$, Fig. 2a, Table S1), demonstrating that the valence effect was larger for

142 self compared to others $\left(\log _{\mathrm{e}}\left(V_{\text {Wilcoxon }}\right)=9.09,95 \% \mathrm{Cl}[0.05,0.38], p=.013\right.$, Fig.S1). This difference

143 was mainly driven by potential positive information (self-other $M=8.56, S E=1.77, t(377)=4.85, p$

$144<.001$; negative information: self-other $M=4.14, S E=1.77, t(377)=2.34, p=.091)$. In sum,

145 individuals' showed highest motivation to seek positive information concerning themselves.

\section{Trait curiosity and information-seeking}

148 Trait curiosity was assessed via the Curiosity and Exploration Inventory-II scale ( ${ }^{8}$, see Methods). As

149 expected $^{8}$, both subscales, stretching and embracing, correlated $(r=0.67,95 \% \mathrm{Cl}[0.58,0.75], p$ $<.001$ ). For this reason, the mean value of all items was taken as a measure of trait curiosity (range $=$ $1.3-4.7, M=3.08)$, with higher values indicating a relatively higher curiosity.

153 Curiosity typically manifests in information-seeking motivation and -behaviors. Indeed, when

154 correlating motivational ratings for self, other, and valence, we found that participants with higher

155 trait curiosity were more motivated to seek information for self overall $(r=0.25,95 \% \mathrm{Cl}[0.10,0.38]$,

$156 p=.003)$, but not about others $(r=0.13,95 \% \mathrm{Cl}[-0.02,0.27], p=.246)$ or by the valence of

157 information (i.e. positive-negative information: $r=-0.05,95 \% \mathrm{Cl}[-0.20,0.10], p>.999 ; p$-values are 
Holm-corrected), demonstrating that trait curiosity relates to information-seeking motivation for self - independent of valence.

160

161 Curiosity and information-seeking relate to mental well-being

162 One of the main aims was to investigate whether and how individuals' curiosity and informationseeking relate to mental well-being during lockdown. Furthermore, we investigated if such potential associations are mediated by loneliness during COVID-19 restrictions.

Firstly, by computing correlations we found that curious individuals who are, on average, more

167 motivated to seek information also reported higher mental well-being at baseline (Warwick

168 Edinburgh Mental Wellbeing Scale (WEMWBS), Fig. 2b,c). Secondly, participants with increased

169 loneliness feelings reported significantly lower mental well-being $(r=-0.60,95 \% \mathrm{Cl}[-0.69,-0.50], p<$

$170.001)$, had lower levels of curiosity $(r=-0.35,95 \% \mathrm{Cl}[-0.47,-0.21], p<.001)$, and were less motivated to seek information about oneself $(r=-0.20,95 \% \mathrm{Cl}[-0.34,-0.05], p=.014)$, p-values are Holmcorrected. These results support a relationship between curiosity measures, well-being and loneliness.

Additionally, we tested whether valence and information-target motives of information-seeking correlated with individual's well-being. There were no significant correlations with valence (positivenegative, $r=-0.07,95 \% \mathrm{Cl}[-0.22,0.08], p>.999)$, information target (self-other, $r=0.12,95 \% \mathrm{Cl}[-$ $0.03,0.26], p=.437)$, or simply information-seeking about others $(r=0.07,95 \% \mathrm{Cl}[-0.08,0.22], p>$

179 .999). In summary, the link between curiosity and well-being was independent of information

180 valence and information target. Therefore, subsequent analyses were focused on information181 seeking for self. 
a

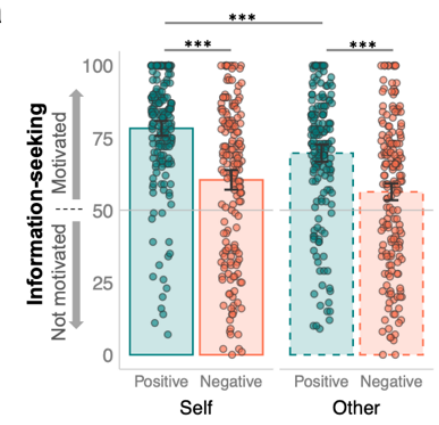

b

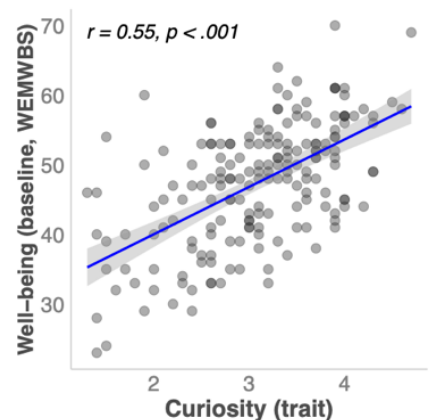

c

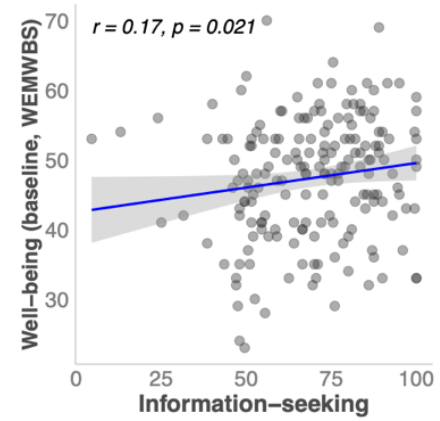

d

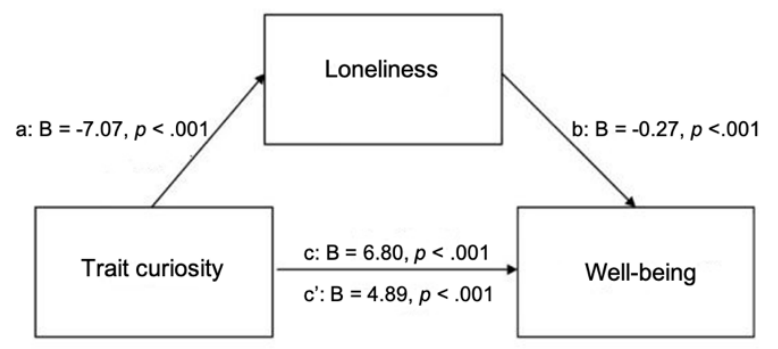

e

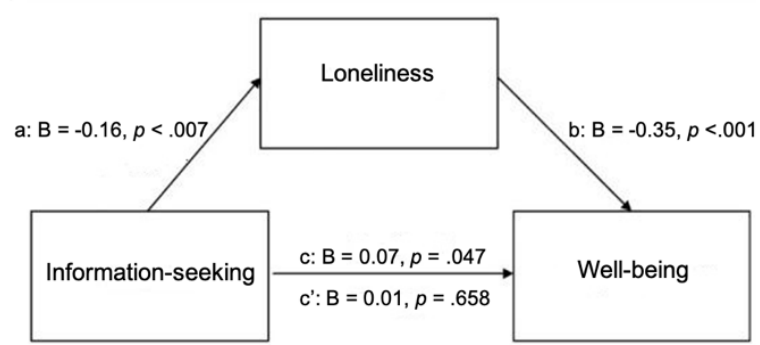
restrictions, we examined whether loneliness mediated this relationship.

Figure 2. Information-seeking, curiosity, individual well-being (WEMWBS) and contributions of loneliness. a) Information-seeking motivation is influenced by valence (positive, negative) and information target (self, other). Dots represent individual ratings. Error bars are SEM. Asterisks $\left(^{*}\right)$ indicate statistically significant differences: ${ }^{* * *} p<.001$. b) Correlation between triat curiosity and well-being. c) Correlation between information-seeking and well-being. $d$ ) Mediation model illustrating loneliness partially mediates the trait curiosity - well-being relationship. e) Mediation model illustrating loneliness fully mediates the information-seeking - well-being relationship. Betas are unstandardized, total effect (c), direct path $\left(c^{\prime}\right)$.

\section{Positive links between curiosity and well-being are mediated by subjective loneliness}

We had preregistered to compute a multiple linear regression to assess the hypothesis that curiosity and information-seeking motivation relate to mental well-being, including loneliness as a covariate. However, as loneliness is integral to the pandemic lockdown and significantly correlates with both measures of interest, we opted for an alternative analysis approach. Specifically, to better understand how curiosity and information-seeking relate to mental well-being in a period with social 
both models revealed loneliness as a mediator. The relationship between trait curiosity and wellbeing was partially mediated by loneliness, as the direct effect reduced in size $\left(c^{\prime}: B=4.89, S E=0.63\right)$ compared to the total effect (c: $B=6.80, S E=0.71$, Fig. $2 d$; bootstrapped indirect effect $\left(a^{*} b\right) B=$ $1.92, S E=0.44, Z=4.35, p<.001, R 2=0.53)$. Interestingly, loneliness fully mediated the effect of information-seeking on well-being ( $R 2=0.38$, bootstrapped indirect effect $\left(a^{*} b\right) B=0.08, S E=0.02$,

$211 Z=2.60, p=.009$, Fig. 2e), such that information-seeking predicted higher mental well-being, only

212 through reducing loneliness.

214 Taken together, we found that the subjective loneliness during COVID-19 pandemic fully mediates

215 the positive relationship between information-seeking and mental well-being, and partially between

216 individual's trait curiosity and well-being. Interestingly, trait curiosity also still had an incremental

217 direct effect on well-being independent of subjective loneliness.

\section{Daily well-being and mood during lockdown is linked to individuals' trait curiosity}

So far, we showed that both trait curiosity and information-seeking behavior are associated with baseline mental well-being (WEMWBS) measured at testday one. Next, we also aimed to investigate whether these curiosity measures assessed at day one could predict individuals' averaged daily wellbeing (i.e. short WEMWBS) and mood (i.e. excitement and anxiety) reported during the rest of the lockdown week, hence have a longer-lasting predictive effect.

Trait curiosity, daily well-being and mood

227 We found a positive correlation between trait curiosity with individuals' average daily well-being (Fig. 3a), and excitement (Fig. 3b), but not with anxiety (Fig. 3c). These associations were also observed when including trait curiosity and loneliness as predictor and covariates for age, gender, 
231 (well-being: beta $=1.06,95 \% \mathrm{Cl}[0.50,1.63], p<.001$; excitement: beta $=0.16,95 \% \mathrm{Cl}[0.03,0.29], p$

$232=.019 ;$ anxiety: beta $=0.08,95 \% \mathrm{Cl}[-0.05,0.21], p=.237)$.

233

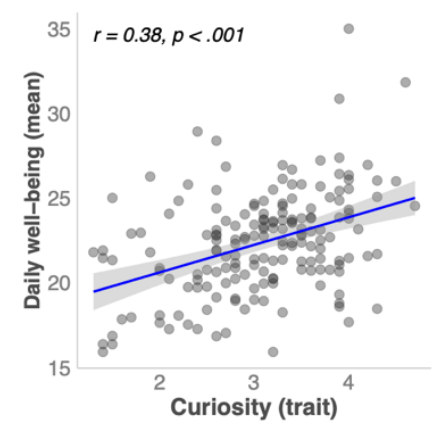

d

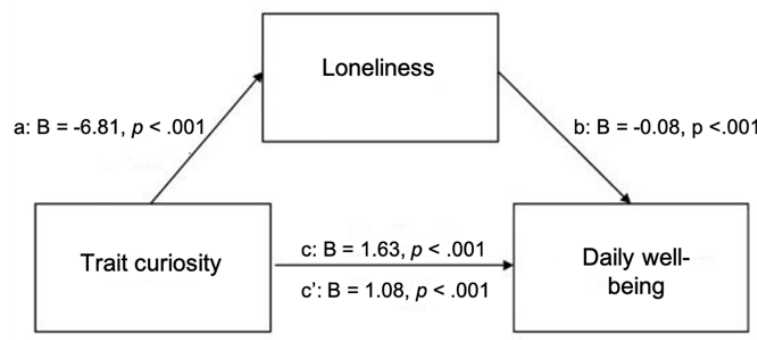

b

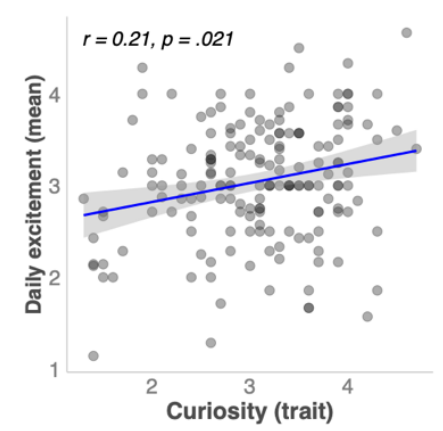

C

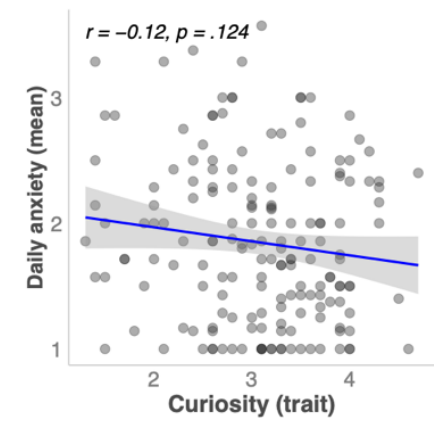

e

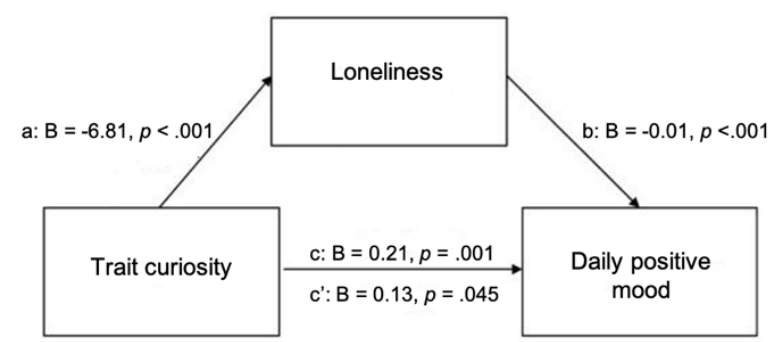

234

235

236

237

238

239

240

241

242 between trait curiosity and daily well-being and excitement (Fig. 3d, 3e).

Figure 3. Associations between trait curiosity, daily well-being and mood. Significant correlations between trait curiosity, daily well-being (a), and daily excitement (b), but not with daily anxiety (c). Mediation models with trait curiosity as predictor and loneliness as mediator predicting daily well-being (d), and daily positive mood (i.e. excitement) (e). Betas are unstandardized, total effect (c), direct path $\left(c^{\prime}\right)$.

Next, we investigated whether loneliness also mediated the relationship between curiosity and daily well-being and excitement. The mediation models revealed a significant indirect effect predicting average daily well-being (bootstrapped indirect effect $\left(a^{*} b\right)$ : $B=0.55, S E=0.15, Z=3.68, p<.001, R 2$ $=0.31$ ), and predicting average daily excitement (bootstrapped indirect effect $\left(a^{*} b\right): B=0.07, S E=$ $0.03, Z=2.74, p=.006, \mathrm{R} 2=0.12$ ), illustrating that loneliness partially mediated the relationship

Information-seeking does not predict daily well-being and mood

Information-seeking overall for self did not significantly predict averaged daily well-being $(F(1,170)=$ 
.598), nor when including covariates (see Supplementary Information (SI)). In sum, the association between information-seeking and individuals' baseline well-being (WEMWBS) was not observed for average well-being, days later into lockdown.

\section{Curiosity, daily dietary intake, and their influence on daily mood}

We preregistered to explore whether there is a link between individual's average daily food intake (i.e. nutritive content) and curiosity to predict daily well-being and mood. Moreover, based on associations between dopamine and curiosity and information-seeking ${ }^{4,5,26,28}$, we explored whether trait curiosity and information-seeking could predict the daily intake days later of large neutral amino acids (LNAA) tyrosine- and phenylalanine (i.e. precursor for dopamine), and tryptophan (precursor for serotonin) relative to other LNAAs ${ }^{32,33}$. We extracted the quantity of macro- and micro-nutrients including LNAAs from the submitted food in the food-diary app (see Methods).

First, exploring whether trait curiosity and information-seeking associated with intake of tyrosine/LNAA including tyrosine- and phenylalanine/LNAA, and tryptophan/LNAA, we ran a linear regression including gender, because of observed gender differences in food intake (see Table S2). Trait curiosity negatively predicted tyrosine- and phenylalanine/LNAA intake (beta $=-0.003, p=$ .017), such that individuals with lower trait curiosity consumed more tyrosine-rich food. Information-seeking motivation also negatively predicted the intake of tyrosine-rich food (i.e. tyrosine $/$ LNAA, beta $=-0.000, p=.014)$. Tryptophan/LNAA ratio was neither predicted by trait curiosity $(p=.151)$, nor information-seeking motivation $(p=.964)$. However, there was a trend for an interaction between trait curiosity and gender predicting tryptophan/LNAA intake ( $p=.064)$, indicating that women with lower trait curiosity tend to consume more tryptophan-rich food (beta = $-0.001, p=.015)$ compared to men (beta $=0.000, p=.777)$. 
Next, we examined whether food intake indexed by certain nutrient compositions (i.e. carbs, fat, simple sugars, fruit and vegetables) contribute to the curiosity - daily well-being and mood link. As information-seeking did not show any association with self-rated daily well-being and mood, we focused on trait curiosity only. We included the nutrient compositions (as mean percentage) and trait curiosity into linear models including potential covariates (e.g. gender, residency, age) to predict daily well-being, excitement, as well as anxiety (i.e. three independent models). Food intake showed no significant main effects and interactions with trait curiosity predicting well-being or excitement (all $p^{\prime} s<0.05$, see Table $\$ 3+S 4$ ). However, we found that sugar intake positively predicted anxiety (beta $=0.25, p=.008$ ), which was influenced by individuals' trait curiosity (interaction: beta $=-0.08, p=.005$, Fig.4, Table S5). Further decomposing this interaction, by comparing the slopes, showed that sugar intake increased anxiety in participants with low trait curiosity, which effect was reversed in participants with high trait curiosity (high sugar, beta $=-0.34$, $Z=-3.64, p<.001)$. This was not observed for mean (beta $=-0.13, Z=-1.98, p=.053$ ) to low sugar intake levels (beta $=0.09, \mathrm{Z}=1.04, p=.308$ ).

291

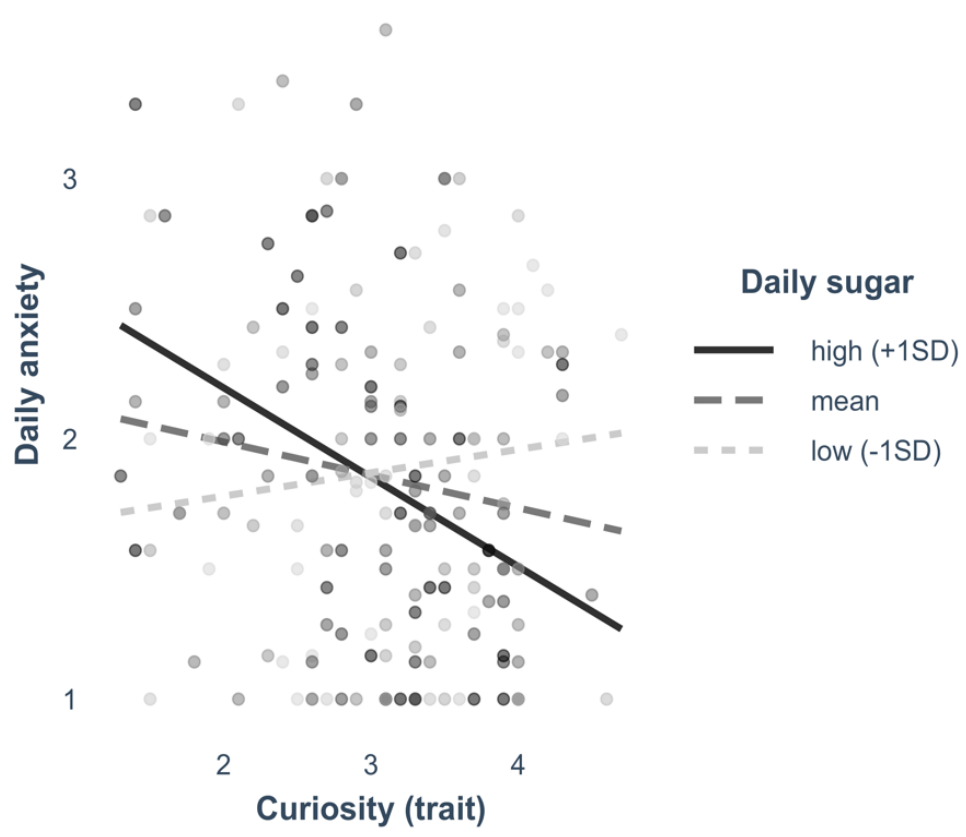

Figure 4. Relationship between trait curiosity and daily anxiety at different levels of sugar intake (high, mean, low). 
298 The COVID-19 pandemic has profoundly affected our daily social lives, physical and mental well-

299 being ${ }^{1,2}$. Trait curiosity and access to adequate information are hypothesized to promote better 300 coping with challenging situations, enhancing well-being, mood, and life satisfaction ${ }^{6-9}$. In the current study, we investigated whether trait curiosity and information-seeking motivation are linked to individuals' mental well-being and mood during lockdown in a global health crisis, encompassed of extreme loneliness and uncertainty. Furthermore, we investigated whether the relationship between curiosity, well-being, and mood is moderated by the food we consume during the lockdown.

307 Our results show that both trait curiosity and information-seeking motivation predicted higher well-

308 being and reduced loneliness during lockdown. In line with previous findings ${ }^{15,16}$, we also found a

309 negative association between loneliness and lower well-being. Interestingly, we found that the

310 association between curiosity and information-seeking with well-being was mediated by individuals'

311 feelings of loneliness. Thus, our data suggests that individuals' information-seeking and curiosity is

312 beneficial for well-being, through reducing loneliness during the lockdown. Moreover, trait curiosity

313 also still predicted well-being independently.

315 Consistent with the broaden-and-build framework ${ }^{11}$, being curious and gathering information may foster positive states and coping with social restrictions by reducing loneliness feelings through

317 increased engagement and exploration. Individual differences in loneliness and resilience have 318 previously been linked with personality traits ${ }^{17,18}$, with people scoring higher on extraversion and 319 openness reporting lower loneliness feelings and higher well-being. Our findings contribute to this, 320 by showing that a person's trait curiosity and information-seeking behavior also predict higher well-

321 being, via diminished impact of loneliness during a socially challenging and uncertain time. 
323 Trait curiosity, but not information-seeking, also predicted daily well-being and positive mood

324 (excitement) on a longer timescale - i.e. averaged across 2-7 observation days into the lockdown. In contrast with trait curiosity ${ }^{8}$, we explicitly asked participants about their motivation for seeking information at the present time, likely capturing their momentary state and motivation to interact with their environment. Hence, this measure may vary within-participants across subsequent days, and consequently might not be a good predictor of daily well-being and mood at later timepoints. Indeed, recent work found that consistency in state curiosity is an important predictor of daily wellbeing ${ }^{34}$. These findings suggest that an individual's trait-level curiosity and consistency in state-level curiosity is important to predict well-being and mood on a daily basis, while the momentary motivation to seek information as a behavioral expression of one's curiosity likely relates to wellbeing and mood on a shorter timescale.

Replicating studies on information-seeking ${ }^{27,35}$, individuals' were more motivated to seek positive

336 rather than negative information. Additionally, we found that this valence-dependent effect was stronger when information concerned oneself than others, and driven mostly for information that was positive but not negative. While people are generally motivated to seek positive information because of the expected positive feelings from having a positive belief ${ }^{27}$, good news about others may provide less strong positive feelings. Likewise, vicarious rewards produce less strong reward-

341 related activation than own rewards ${ }^{36}$. However, social information concerning negative outcomes

342 can still be important in novel situations and when the quality of information is uncertain, to avoid being exposed to risks from first-hand experience.

345 When feeling lonely, individuals may even be more motivated to seek information about others.

346 Surprisingly, our results showed a non-significant negative relation between information-seeking

347 about others and loneliness, suggesting that feeling lonely does not enhance the willingness to know 348 more about others' outcomes. This is in slight contrast to other findings ${ }^{16}$, demonstrating that 
349 people with higher loneliness over-attend to negative social information in the environment. We

350 also did not find a correlation between loneliness and the motivation to seek negative information

351 about others. Instead of providing participants with information, we asked participants whether they

352 actively wanted information about others. The difference between passive information and active

353 information-seeking could explain why we did not find a relation between loneliness and

354 information-seeking concerning others.

355

356 Despite showing a valence-dependent motivation to seek information, the link between mental well-

357 being and information-seeking motivation was independent of valence. Seeking information, both

358 positive and negative, can help reduce uncertainty ${ }^{5}$. Moreover, previous findings reported that

359 individuals who are more curious are better capable in regulating and controlling their emotions,

360 and report higher well-being ${ }^{8}$. Hence, our data further suggest that higher well-being relates to high

361 curiosity and motivation to explore knowledge for both positively and negatively valenced

362 information.

363

364 Besides the social context, the lockdown also resulted in lifestyle changes including diet ${ }^{37}$. Healthy eating can protects one's mental health and mood, particularly in challenging and stressful times ${ }^{19-}$ ${ }^{21}$, with stress predicting lower quality food intake full of carbs, sugars, and fat ${ }^{29,30}$. Nonetheless, in a

367 previous study ${ }^{19}$, fruit and vegetable intake increased well-being and curiosity, although sugar

368 intake decreased well-being but increased curiosity. We explored whether food intake contributed

369 to the effects of curiosity on mood and well-being. In contrast to Conner and colleagues ${ }^{19}$, we did

370 not observe a relation between fruit and vegetable intake and curiosity, nor did it predict mood or

371 well-being. However, we found a significant interaction between sugar intake and trait curiosity

372 predicting negative mood during the lockdown. Food high in sugar predicted higher anxiety among

373 people with low trait curiosity, and lower anxiety in those with high trait curiosity. This suggests that

374 high trait curiosity may buffer negative effects of high-sugar on mood, whereas individuals low in 
375 trait curiosity - who typically explore less and regulate their emotions less well, may be particularly

376 susceptible to the negative effects of high-sugar ${ }^{38}$. Consistent with this, previous studies have linked

377 high-sugar/fat intake to enhanced anxiety (for review, ${ }^{39}$ ) and changes in dopamine precursor

378 availability ${ }^{40}$. Possibly, curiosity compensates the effects of sugar on anxiety through its effect on

379 positive mood, motivation and enhanced mesolimbic dopamine activity ${ }^{8,27}$. Compared to prior food

380 diary studies e.g. ${ }^{19}$ that assessed self-reported food intake on predefined categories (i.e. sweets, fruit,

381 vegetables, and chips), our study takes a more holistic approach by extracting nutrients as dietary

382 components from the quantity of each food and beverage participants consumed over the day for

383 maximum a week, using a food-diary app.

384

385 Protein-rich food contains high amounts of LNAAs including dopamine and serotonin precursors ${ }^{32,41}$.

386 The reward circuitry, in particular dopamine, have been associated with curiosity and information-

387 seeking ${ }^{27,42}$. We found that individuals with lower trait curiosity and information-seeking motivation

388 consumed more tyrosine-rich food, providing an indirect link between dopamine and curiosity.

389 Individuals low in curiosity may require foods high in tyrosine to increase dopamine synthesis to

390 regulate their information-seeking motivation and mood. Supporting this, atypical information-

391 seeking motivation has been linked to abnormal dopamine functioning. For instance, enhancing

392 dopamine through levodopa was found to increase information gain for negative non-instrumental

393 information, without affecting mood ${ }^{43}$. Moreover, there was no observed link between curiosity and

394 food intake containing high-tryptophan levels, potentially suggesting that tryptophan plays a less

395 prominent role in curiosity, or could have specific effects that our measures could not capture e.g. 44.

396 The causal effect of our findings remain open. Future studies should test for the direction of effects

397 of diet and curiosity, for example, using a dietary intervention containing high/low precursors of

398 dopamine and serotonin.

399 
400 Some limitations and constraints should be considered. First, curiosity and loneliness were only

401 measured once at the beginning of the study, therefore we cannot reveal within-person changes

402 over time and test how they relate to daily changes in well-being and mood during lockdown.

403 Second, despite the positive contributions of curiosity and food on well-being and mood, these

404 findings are strictly correlational and we cannot draw a causal link. It is plausible that the

405 relationships reported here are bi-directional (e.g. food predict curiosity, as shown by for behavior,

$406{ }^{32}$ ). Intervention experiments are required to establish whether a bi-directional association exists.

407 Third, daily food and mood measures were based on self-report, which suffers from reliability issues

408 and accuracy. Despite this, a strength is that it provided a rich dataset with multiple daily

409 momentary observations, representing a more ecological representation of people's daily food

410 intake under real-life conditions.

411

412 In conclusion, trait curiosity and information-seeking motivation predicted higher well-being,

413 investigated during lockdown of COVID-19 pandemic. Importantly, reduced loneliness played an

414 underlying mediating role. Furthermore, high-sugar intake worsened mood during lockdown,

415 specifically in people with low trait curiosity. The causal and exact direction of effects reported here

416 need to be corroborated by future research, and whether these effects can generalize to other social

417 challenging contexts. Our results suggest that curiosity interacts with lifestyle measures (loneliness

418 and diet), indicating the potential to modulate each of these players to potentially increase well-

419 being and mood during a time of crisis.

420

421 
424 Hundred eighty-three participants were accepted to partake in the online study in the period from 10 November - 23 December 2020 during light and strict lockdown phases in Germany and Austria, respectively. During these lockdown periods, people were asked to reduce social contacts to the necessary minimum and mainly work from home (see https://www.bundesregierung.de/bregde/themen/coronavirus/corona-massnahmen-1734724; from: 28.10.2020; https://www.sozialministerium.at/Informationen-zum-Coronavirus/Coronavirus---AktuelleMaßnahmen.html, from 17.11.2020)). Participants were recruited via Prolific platform (https://prolific.co/). Inclusion criteria were living in Germany or Austria at the time of the study, fluent in German, and no history of psychiatric illness. For the second part of the online study, participants had to log their food intake and their mood daily via a smartphone app (i.e. FoodApp). A priori inclusion criteria were set to a minimum of four days of food and mood entries per person. However, as we preregistered to calculate the average mood and food intake, and to minimize loss of valuable data, we decided to restrict our sample to a minimum of two completed entries for food intake and mood ratings. This resulted in data of a total of 172 participants. Participants received $£ 28$ for their participation. This study was preregistered (https://osf.io/xfcwb; https://osf.io/tgpr4) and approved by the ethical committee from Humboldt University of Berlin (reference code 202022).

\section{Questionnaires}

443

\section{Trait curiosity} Individual's trait curiosity was assessed via a validated questionnaire (Curiosity and Exploration Inventory-II (CEI-II); 10 items, ${ }^{8}$ ). This scale assesses people's disposition to explore unsolved

447 problems, unpredictable challenges, and unfamiliar experiences, all out of a sense of curiosity about 448 the world. Example items include, "I actively seek as much information as I can in new situations" 
and "I prefer jobs that are excitingly unpredictable." Answers are given on a 5-point scale $(1=$ very slightly or not at all; 5 = extremely).

451

Information seeking motivation

453 Four questions assessing individuals' motivation to seek information; individuals rated their motivation on a sliding bar (from 0 - 100 (i.e. not motivated to seek information - highly motivated to seek information) for positive/negative expected outcomes related to oneself and about other people; see SI for questions and rating).

Mental-well-being (baseline), loneliness, affective health and COVID-19-related impact

Participants completed standard self-report questionnaires assessing a range of mental and affective health symptoms. These included mental well-being (Warwick Edinburgh Mental Wellbeing Scale (WEMWBS) ${ }^{45}$, perceived loneliness (UCLA Loneliness Scale ${ }^{46}$, depression (Beck's Depression Inventory ${ }^{47}$, trait anxiety (State Trait Anxiety Inventory ${ }^{48}$ ), perceived stress (Perceived Stress Questionnaires ${ }^{49}$ ), and also other lifestyle-related questions that were part of a larger study (preregistered under https://osf.io/nqhjf) that were not analyzed here. Furthermore, we assessed the impact COVID-19 had on participants' lives such as how well they complied with the rules, what their current work situation was (e.g. home-office) and whether they or others they knew contracted the virus (see SI for details).

Daily food, well-being and mood

Once a day after 17:00h participants are asked questions about their mental well-being, mood, and lifestyle (e.g. activity) via the food-diary app. 
levels of well-being. Mood was assessed based on the Positive Affect Negative Affect Scale ${ }^{50}$.

Participants were asked to rate one item of each on a scale of 1 to 5 ; for positive affect feeling excited and for negative affect feeling anxious. Furthermore, participants were also asked to rate how well they slept (sleep), how active they were that day (active) and about quantity and satisfaction of their social interactions that day (social) on a visual analog scale from 1 to 100.

480

Food intake was assessed via self-report using the food-diary app. Here, participants provided the following information: date and time, type of meal (e.g. breakfast, lunch, snack), whether they ate alone or in company, food item and quantity (in grams or milliliters). Participants are asked to complete the daily food diary and mood questions for 7 days. The output allowed us to extract caloric content and information on macro- and micronutrients of the consumed food using the German BLS data table ${ }^{51}$. We excluded observations from analysis that fel outside the plausible daily energy (caloric) intake, i.e. $<500 \mathrm{kcal} /$ day and $>3500 \mathrm{kcal} /$ day for women, and $<800 \mathrm{kcal} /$ day or $>$ $4000 \mathrm{kcal} /$ day for men ${ }^{52}$. multiplied the daily intake of carbohydrate (g/day) by $4 \mathrm{kcal}$, fat intake by $9 \mathrm{kcal}$, sugars by $2 \mathrm{kcal}$ to obtain the daily energy derived from each macronutrient (Table S2). Tyrosine and tryptophan to LNAA ratios were calculated by dividing the quantity of tyrosine and of tryptophan by the sum of the other LNAAs (equations 1a,1b,2), and used as a proxy of brain tyrosine and tryptophan levels and ultimately brain dopamine and serotonin levels, respectively ${ }^{32}$. 
505 After providing instructions and written consent, participants were invited to complete a battery of questionnaires online assessing trait curiosity, information-seeking motivation, mental health (e.g. mental well-being, loneliness, stress, anxiety), and lifestyle behaviors (including sleep, activity, and social factors).

Next, participants were asked to install a food-diary app provided by us on their smartphone, and

511 submit a daily diary of their food consumption (i.e. daily intake of food items and beverages) in the

512 app, from which we extracted the total calories, macro- \& micronutrients per meal per day. They

513 were also asked to rate their well-being and mood (on a scale from 1-7) once a day for a

514 maximimum period of a week using the same app. Furthermore, daily subjective experience

515 regarding sleep quality, activity level and social interactions were also recorded.

517 Due to the timing of the lockdown restrictions, we first conducted the online study in Germany as preregistered. While the German study was ongoing, the government in Austria announced an upcoming lockdown. Therefore, we decided to repeat the same experiment in Austria (separately preregistered with same questions and measures). After data collection and because of the small sample in Austria, we instead merged the data of the German sample and the first Austrian sample and included a predictor of residence country in the analysis to account for potential differences in experienced lockdown measures. We chose Austria, as Austria and Germany are geologically close, share the same native language, and are highly comparable both on a social and economic level. 
531 Mental well-being was measured once at the beginning of the study (baseline, WEMWBS) and

532 through the app as a day-to-day well-being measure (daily well-being, short WEMWBS). Daily measures of well-being, excitement and anxiety were each averaged per person over the days logged. To test the relationships between trait curiosity, information-seeking motivation and the dependent variables mental well-being (baseline and daily), mood (excitement, anxiety) and food intake, we computed non-parametric (Spearman) correlations and linear regressions. To control for individual differences, we included covariates age, gender and country of residence in the linear models. To avoid biased coefficients due to high correlation, we did not include baseline well-being scores as covariate in the model to predict average daily well-being, and perceived stress (PSQ) in combination with trait anxiety to predict daily anxiety. Furthermore, we investigated which motives drive information-seeking motivation. To test this, we ran a mixed effect model on the ratings for

542 information-seeking with within-subject predictors for the valence and information target, including

543 by participant random intercept and random slopes for the within-subject predictors. Analysis were performed using "Ime4" (version 1.1.27) ${ }^{54}$ and "ImerTest" (version 3.1.3) $)^{55}$. P-values for linear models were computed using Kenward-Roger approximation. Post-hoc analyses were done using "emmeans" (version 1.6.1) ${ }^{56}$, and "interactions" (version 1.1.0) ${ }^{57}$ for simple slope comparisons, and adjusted for multiple comparisons using the Tukey where relevant. For correlations $p$-values were adjusted using Holm correction (1979). Note in the preregistration we reported to use the Bonferroni as correction for multiple comparisons, however, we decided for Tukey and Holm instead as it is considered uniformly more powerful. Table and plots were created using "gtsummary"

551 (version 1.4.1) $)^{58}$ and "ggplot2" (version 3.3.3) ${ }^{59}$. Mediation analyses were performed to test whether

552 the relationship between information-seeking, trait curiosity and the dependent variables was 553 mediated by feelings of loneliness. Bootstrapping (1000 samples) was performed as implemented in the "lavaan"(version 0.6.8) 
557 The anonymized data is available from the corresponding authors upon request.

\section{$558 \quad$ References}

559 1. Brooks, S. K. et al. The psychological impact of quarantine and how to reduce it: rapid review

$560 \quad$ of the evidence. Lancet 395, 912-920 (2020).

561 2. Gubler, D. A., Makowski, L. M., Troche, S. J. \& Schlegel, K. Loneliness and Well-Being During

562

563

564

565

566

567

568

569

570

571

572

573

574

575

576

577

578 the Covid-19 Pandemic: Associations with Personality and Emotion Regulation. J. Happiness Stud. 1-20 (2020) doi:10.1007/s10902-020-00326-5.

3. Bendau, A. et al. Associations between COVID-19 related media consumption and symptoms of anxiety, depression and COVID-19 related fear in the general population in Germany. Eur. Arch. Psychiatry Clin. Neurosci. 271, 283-291 (2021).

4. Sharot, T. \& Sunstein, C. R. How people decide what they want to know. Nat. Hum. Behav. 4, 14-19 (2020).

5. van Lieshout, L. L., de Lange, F. P. \& Cools, R. Why so curious? Quantifying mechanisms of information seeking. Curr. Opin. Behav. Sci. 35, 112-117 (2020).

6. Loewenstein, G. The psychology of curiosity: A review and reinterpretation. Psychol. Bull. 116, 75-98 (1994).

7. Kashdan, T. B. \& Steger, M. F. Curiosity and pathways to well-being and meaning in life: Traits, states, and everyday behaviors. Motiv. Emot. 31, 159-173 (2007).

8. Kashdan, T. B. et al. The curiosity and exploration inventory-II: Development, factor structure, and psychometrics. J. Res. Pers. 43, 987-998 (2009).

9. Kidd, C. \& Hayden, B. Y. The Psychology and Neuroscience of Curiosity. Neuron vol. 88 449460 (2015).

10. Peterson, C., Ruch, W., Beermann, U., Park, N. \& Seligman, M. E. P. Strengths of character, orientations to happiness, and life satisfaction. J. Posit. Psychol. 2, 149-156 (2007).

11. Fredrickson, B. L. The broaden-and-build theory of positive emotions. Philos. Trans. R. Soc. London. Ser. B Biol. Sci. 359, 1367-1377 (2004).

12. Kawachi, I. \& Berkman, L. F. Social Ties and Mental Health. Journal of Urban Health: Bulletin of the New York Academy of Medicine vol. 78 (2001).

13. Rendell, L. et al. Why Copy Others? Insights from the Social Learning Strategies Tournament. Science (80-. ). 328, 208-213 (2010).

14. Boyd, R., Richerson, P. J. \& Henrich, J. The cultural niche: Why social learning is essential for human adaptation. Proc. Natl. Acad. Sci. 108, 10918-10925 (2011).

15. Hawkley, L. C. \& Cacioppo, J. T. Loneliness matters: A theoretical and empirical review of consequences and mechanisms. Ann. Behav. Med. 40, 218-227 (2010).

16. Cacioppo, J. T. \& Hawkley, L. C. Perceived social isolation and cognition. Trends Cogn. Sci. 13, 447-454 (2009).

17. Buecker, S., Maes, M., Denissen, J. J. A. \& Luhmann, M. Loneliness and the Big Five Personality Traits: A Meta-analysis. Eur. J. Pers. 34, 8-28 (2020).

18. Modersitzki, N., Phan, L. V., Kuper, N. \& Rauthmann, J. F. Who Is Impacted? Personality Predicts Individual Differences in Psychological Consequences of the COVID-19 Pandemic in Germany. Soc. Psychol. Personal. Sci. (2020) doi:10.1177/1948550620952576.

19. Conner, T. S., Brookie, K. L., Richardson, A. C. \& Polak, M. A. On carrots and curiosity: Eating fruit and vegetables is associated with greater flourishing in daily life. Br. J. Health Psychol. 20, 413-427 (2015).

20. Głąbska, D., Guzek, D., Groele, B. \& Gutkowska, K. Fruit and vegetable intake and mental health in adults: A systematic review. Nutrients vol. 12115 (2020).

21. Begdache, L., Sadeghzadeh, S., Derose, G. \& Abrams, C. Diet, exercise, lifestyle, and mental 
distress among young and mature men and women: A repeated cross-sectional study. Nutrients 13, 1-18 (2021).

22. Kroes, M. C. W. et al. Food can lift mood by affecting mood-regulating neurocircuits via a serotonergic mechanism. Neuroimage 84, 825-832 (2014).

23. Salamone, J. D. \& Correa, M. The Mysterious Motivational Functions of Mesolimbic Dopamine. Neuron vol. 76 470-485 (2012).

24. Aquili, L. The Role of Tryptophan and Tyrosine in Executive Function and Reward Processing. Int. J. Tryptophan Res. 13, 1-13 (2020).

25. Cools, R. et al. Tryptophan Depletion Disrupts the Motivational Guidance of Goal-Directed Behavior as a Function of Trait Impulsivity. Neuropsychopharmacol. 2005 307 30, 1362-1373 (2005).

26. Bromberg-Martin, E. S. \& Monosov, I. E. Neural circuitry of information seeking. Current Opinion in Behavioral Sciences vol. 35 62-70 (2020).

27. Charpentier, C. J., Bromberg-Martin, E. S. \& Sharot, T. Valuation of knowledge and ignorance in mesolimbic reward circuitry. Proc. Natl. Acad. Sci. 115, E7255-E7264 (2018).

28. Gruber, M. J., Gelman, B. D. \& Ranganath, C. States of curiosity modulate hippocampusdependent learning via the dopaminergic circuit. Neuron 84, 486-96 (2014).

29. Bordier, C., Klein, S., Le Conte, Y., Barron, A. B. \& Alaux, C. Stress decreases pollen foraging performance in honeybees. J. Exp. Biol. 221, (2018).

30. Roberts, C. J., Campbell, I. C. \& Troop, N. Increases in weight during chronic stress are partially associated with a switch in food choice towards increased carbohydrate and saturated fat intake. Eur. Eat. Disord. Rev. 22, 77-82 (2014).

31. Terenzi, D., Liu, L., Bellucci, G. \& Park, S. Q. Determinants and modulators of human social decisions. Neurosci. Biobehav. Rev. 128, 383-393 (2021).

32. Strang, S. et al. Impact of nutrition on social decision making. Proc. Natl. Acad. Sci. U. S. A. 114, 6510-6514 (2017).

33. Liu, L. et al. Eating to dare - Nutrition impacts human risky decision and related brain function. Neuroimage 233, 117951 (2021).

34. Lydon-Staley, D. M., Zurn, P. \& Bassett, D. S. Within-person variability in curiosity during daily life and associations with well-being. J. Pers. 88, 625-641 (2020).

35. Marvin, C. B. \& Shohamy, D. Curiosity and Reward: Valence Predicts Choice and Information Prediction Errors Enhance Learning. (2016) doi:10.1037/xge0000140.

36. Morelli, S. A., Sacchet, M. D. \& Zaki, J. Common and distinct neural correlates of personal and vicarious reward: A quantitative meta-analysis. Neuroimage 112, 244-253 (2015).

37. Ingram, J., Maciejewski, G. \& Hand, C. J. Changes in Diet, Sleep, and Physical Activity Are Associated With Differences in Negative Mood During COVID-19 Lockdown. Front. Psychol. 0, 2328 (2020).

38. Marty, L., Lauzon-Guillain, B. de, Labesse, M. \& Nicklaus, S. Food choice motives and the nutritional quality of diet during the COVID-19 lockdown in France. Appetite 157, 105005 (2021).

39. Jacques, A. et al. The impact of sugar consumption on stress driven, emotional and addictive behaviors. Neurosci. Biobehav. Rev. 103, 178-199 (2019).

40. Hartmann, H. et al. Preliminary evidence for an association between intake of high-fat highsugar diet, variations in peripheral dopamine precursor availability and dopamine-dependent cognition in humans. J. Neuroendocrinol. 32, (2020).

41. Wurtman, R. J. et al. Effects of normal meals rich in carbohydrates or proteins on plasma tryptophan and tyrosine ratios. Am. J. Clin. Nutr. 77, 128-132 (2003).

42. Bromberg-Martin, E. S. \& Hikosaka, O. Lateral habenula neurons signal errors in the prediction of reward information. Nat. Neurosci. 14, 1209-1216 (2011).

43. Vellani, V., de Vries, L. P., Gaule, A. \& Sharot, T. A selective effect of dopamine on information-seeking. Elife 9, 1-14 (2020). 
666

667

668

669

670

671

672

673

674

675

676

677

678

679

680

681

682

683

684

685

686

687

688

689

690

691

692

693

694

695

696

44. Livermore, J. J. et al. Selective effects of serotonin on choices to gather more information. J. Psychopharmacol. 269881121991571 (2021) doi:10.1177/0269881121991571.

45. Lang, G. \& Bachinger, A. Validation of the German Warwick-Edinburgh Mental Well-Being Scale (WEMWBS) in a community-based sample of adults in Austria: a bi-factor modelling approach. doi:10.1007/s10389-016-0778-8.

46. Döring, N. \& Bortz, J. Psychometrische Einsamkeitsforschung: Deutsche Neukonstruktion der UCLA Loneliness Scale [Psychometric research on loneliness: A new German version of the University of California at Los Angeles (UCLA) Loneliness Scale]. Diagnostica 39, 224-239 (1993).

47. Hautzinger, M., Bailer, M., Worall, H. \& Keller, F. Beck-Depressions-Inventar (BDI). (1994).

48. Grimm, J. State-Trait-Anxiety Inventory nach Spielberger. Deutsche Lang- und Kurzversion. (2009).

49. Fliege, H., Rose, M., Arck, P., Levenstein, S. \& Klapp, B. F. Validierung des 'Perceived Stress Questionnaire' (PSQ) an einer deutschen Stichprobe. Diagnostica 47, 142-152 (2001).

50. Janke, S. \& Glöckner-Rist, A. Deutsche Version der Positive and Negative Affect Schedule (PANAS). Zusammenstellung sozialwissenschaftlicher Items und Skalen (2014) doi:10.6102/zis146.

51. Dehne, L. I., Klemm, C., Henseler, G., Bögl, K. W. \& Hermann-Kunz, E. Der Bundeslebensmittelschlüssel (BLS II.2). Bundesgesundheitsblatt 1997405 40, 203-206 (1997).

52. Banna, J. C., McCrory, M. A., Fialkowski, M. K. \& Boushey, C. Examining Plausibility of SelfReported Energy Intake Data: Considerations for Method Selection. Front. Nutr. 4, (2017).

53. WC, W., GR, H. \& LH, K. Adjustment for total energy intake in epidemiologic studies. Am. J. Clin. Nutr. 65, (1997).

54. Bates, D., Mächler, M., Bolker, B. \& Walker, S. Fitting Linear Mixed-Effects Models Using Ime4. J. Stat. Softw. 67, 1-48 (2015).

55. Kuznetsova, A., Brockhoff, P. B. \& Christensen, R. H. B. ImerTest Package: Tests in Linear Mixed Effects Models. J. Stat. Softw. 82, 1-26 (2017).

56. Lenth, R. V., Singmann, H., Love, J., Buerkner, P. \& Herve, M. emmeans: Estimated Marginal Means, aka Least-Squares Means. (2018) doi:10.1080/00031305.1980.10483031>.License.

57. Long, J. A. interactions: Comprehensive, User-Friendly Toolkit for Probing Interactions. (2019).

58. Sjoberg, D. D. et al. gtsummary: Presentation-Ready Data Summary and Analytic Result Tables. (2021).

59. Wickham, H. ggplot2: Elegant Graphics for Data Analysis. (2016).

60. Rosseel, Y. Lavaan: An R package for structural equation modeling. J. Stat. Softw. 48, (2012).

\section{Acknowledgements}

The present study was funded by the grants from the German Ministry of Education and Research (BMBF) and the State of Brandenburg (S.Q.P.: DZD and FKZ; 82DZD03C2G, 82DZD03D03, and DZDG16001, 82DZD0C2G). 


\section{Author Contribution Statement}

698 A.L.V., A.K.M. and S.Q.P. designed the study; A.L.V. and A.K.M. performed the experiment; A.L.V.

699 analyzed the data and prepared the figures; A.L.V. writing-original draft preparation; A.L.V., A.K.M.,

$700 \quad$ D.T., S.Q.P. writing-review and editing; S.Q.P. funding acquisition.

701

702 Competing Interests

The authors declare no competing interests. 


\section{Supplementary Information}

704

705

Results

706

707

Information-seeking motives

708

709

Table S1. Mixed effect model for information-seeking

\begin{tabular}{lllll}
\hline Predictors & & & & \\
& Estimates & $95 \% \mathrm{Cl}$ & Statistic & -value \\
\hline Intercept & 66.22 & $63.91,68.52$ & 56.70 & $<0.001$ \\
Valence & 7.81 & $5.92,9.70$ & 8.16 & $<0.001$ \\
Information target & 3.17 & $1.78,4.57$ & 4.48 & $<0.001$ \\
Valence * Information target & 1.11 & $0.06,2.14$ & 2.10 & 0.037 \\
& & & & \\
$\mathrm{~N}_{\text {subjects }}$ & 183 & & & \\
\hline
\end{tabular}

710

Note. Contrasts were set-to-sum. Positive valence and Self as Information target were set to 1.

714

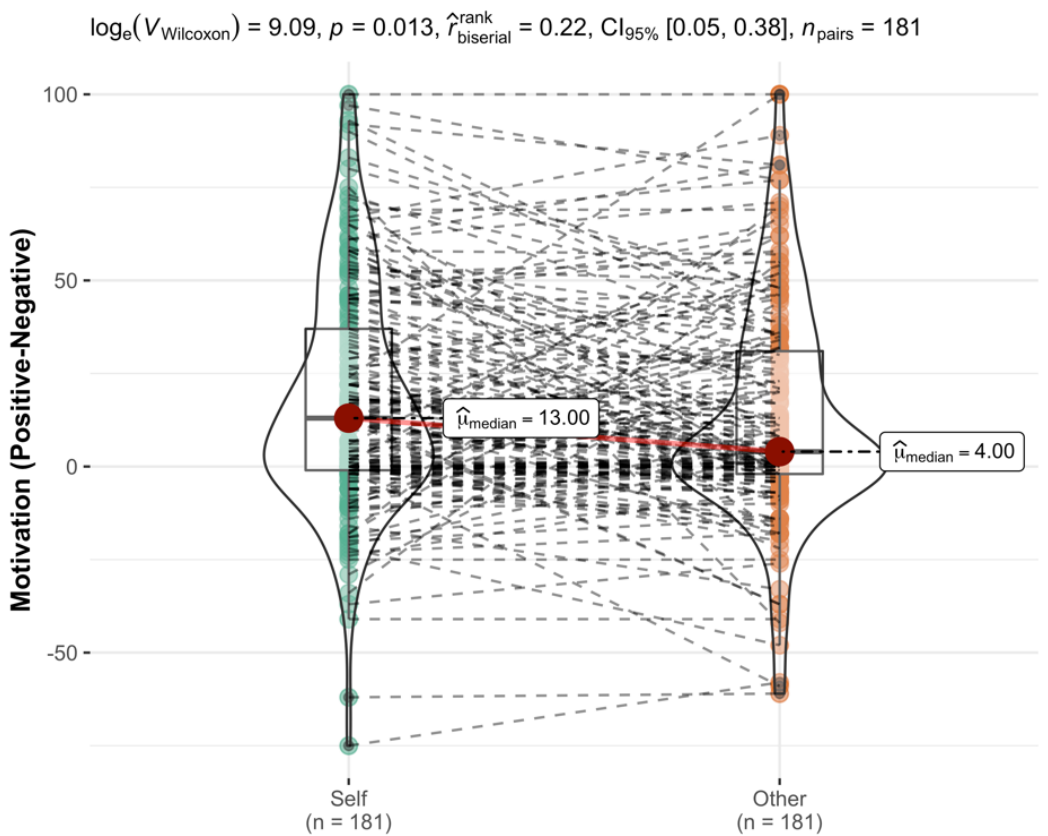

Figure S1. Motivation to seek information that is expected to be positive rather than negative, for Self and about Others. 


\section{Daily well-being and mood}

Information-seeking: including loneliness and covariates for age, gender, residency into the model information-seeking for self did not significantly predict daily mental well-being $(F(1,166)=0.014, p$ $=.907)$, daily excitement $(F(1,166)=1.96, p=.163)$, and daily anxiety $(F(1,165)=0.14, p=.705)$.

\section{Curiosity and daily food intake}

Table. S2. Descriptives of food composition and behavior, split for gender

\begin{tabular}{|c|c|c|c|c|}
\hline Characteristic & Overall, $\mathrm{N}=172^{1}$ & male, $\mathrm{N}=103^{1}$ & female, $N=69^{1}$ & p-value ${ }^{2}$ \\
\hline Calories & $1,659.23(483.42)$ & $1,787.20(465.34)$ & $1,467.28(448.00)$ & $<0.001$ \\
\hline Fat (\%) & $35.48(6.43)$ & $35.53(5.45)$ & $35.40(7.72)$ & 0.9 \\
\hline Carbs (\%) & $46.34(7.06)$ & $45.66(6.79)$ & $47.36(7.39)$ & 0.12 \\
\hline Protein (\%) & $16.82(3.47)$ & $17.61(3.72)$ & $15.64(2.68)$ & $<0.001$ \\
\hline Sugars (\%) & $5.92(3.13)$ & $5.37(3.08)$ & $6.76(3.03)$ & 0.004 \\
\hline $\begin{array}{l}\text { Fruit \& Vegetables } \\
\text { (g/1000kcal) }\end{array}$ & $0.01(0.01)$ & $0.01(0.01)$ & $0.01(0.01)$ & $<0.001$ \\
\hline Curiosity (trait) & $3.08(0.75)$ & $3.11(0.65)$ & $3.02(0.88)$ & 0.4 \\
\hline Information-seeking self & 69.25 (18.17) & $67.29(18.31)$ & $72.17(17.70)$ & 0.085 \\
\hline Daily well-being & $22.36(3.04)$ & $22.49(3.02)$ & $22.16(3.09)$ & 0.5 \\
\hline Daily excitement & $3.04(0.65)$ & $3.09(0.59)$ & $2.98(0.72)$ & 0.3 \\
\hline Daily anxiety & $1.85(0.64)$ & $1.73(0.63)$ & $2.02(0.62)$ & 0.003 \\
\hline
\end{tabular}

${ }^{1}$ Mean (SD), by gender outlier values are winsorized

${ }^{2}$ Two Sample t-test

$\%$ daily energy derived

Table S3. Full model predicting daily well-being levels

\begin{tabular}{|c|c|c|c|c|}
\hline \multirow[b]{2}{*}{ Predictors } & \multicolumn{4}{|c|}{ Daily well-being (mean) } \\
\hline & Estimates & $95 \% \mathrm{Cl}$ & Statistic & $p$-value \\
\hline (Intercept) & 27.38 & $-16.37,71.14$ & 1.24 & 0.218 \\
\hline Curiosity (trait) & -1.39 & $-14.79,12.01$ & -0.21 & 0.838 \\
\hline Carbohydrates & -0.09 & $-0.62,0.44$ & -0.33 & 0.739 \\
\hline Fat & 0.02 & $-0.57,0.61$ & 0.07 & 0.948 \\
\hline Sugar & -0.34 & $-1.18,0.50$ & -0.81 & 0.421 \\
\hline Fruit and Vegetables & 0.01 & $-0.02,0.03$ & 0.58 & 0.560 \\
\hline Age & -0.00 & $-0.05,0.05$ & -0.08 & 0.933 \\
\hline Gender & 0.26 & $-0.20,0.73$ & 1.12 & 0.265 \\
\hline Residency (GER, AT) & -0.03 & $-0.50,0.45$ & -0.11 & 0.912 \\
\hline Loneliness & -0.08 & $-0.11,-0.05$ & -5.7 & $<0.001$ \\
\hline Curiosity (trait) * Carbohydrates & 0.05 & $-0.12,0.21$ & 0.56 & 0.575 \\
\hline Curiosity (trait) * Fat & -0.00 & $-0.18,0.18$ & -0.03 & 0.972 \\
\hline Curiosity (trait) * Sugar & 0.12 & $-0.13,0.38$ & 0.94 & 0.347 \\
\hline Curiosity (trait) * Fruit and Vegetables & -0.00 & $-0.01,0.01$ & -0.61 & 0.545 \\
\hline Observations & \multicolumn{4}{|l|}{170} \\
\hline $\mathrm{R}^{2} / \mathrm{R}^{2}$ adjusted & \multicolumn{4}{|c|}{$0.345 / 0.290$} \\
\hline
\end{tabular}

Note: Trait curiosity remained significant (t(164)=3.72, $p<.001$ ) in the reduced (winning) model (including loneliness, age, gender, residency) based on model comparison, but for completeness of the food variables, we report the full model here. 
Table S4. Full model predicting daily excitement levels

\begin{tabular}{|c|c|c|c|c|}
\hline \multirow[b]{2}{*}{ Predictors } & \multicolumn{4}{|c|}{ Daily excitement (mean) } \\
\hline & Estimates & $95 \% \mathrm{Cl}$ & Statistic & $p$-value \\
\hline (Intercept) & 2.80 & $-7.45,13.04$ & 0.54 & 0.591 \\
\hline Curiosity (trait) & 0.50 & $-2.64,3.63$ & 0.31 & 0.755 \\
\hline Carbohydrates & 0.00 & $-0.12,0.13$ & 0.08 & 0.940 \\
\hline Fat & 0.03 & $-0.11,0.17$ & 0.41 & 0.683 \\
\hline Sugar & -0.11 & $-0.30,0.09$ & -1.10 & 0.275 \\
\hline Fruit and Vegetables & 0.00 & $-0.01,0.01$ & 0.11 & 0.915 \\
\hline Age & -0.02 & $-0.03,-0.01$ & -3.06 & 0.003 \\
\hline Gender & 0.01 & $-0.10,0.12$ & 0.20 & 0.839 \\
\hline Residency (GER, AT) & 0.04 & $-0.08,0.15$ & 0.63 & 0.529 \\
\hline Loneliness & -0.01 & $-0.02,-0.00$ & -2.97 & 0.003 \\
\hline Curiosity (trait) * Carbohydrates & -0.00 & $-0.04,0.04$ & -0.13 & 0.894 \\
\hline Curiosity (trait) * Fat & -0.01 & $-0.05,0.03$ & -0.49 & 0.627 \\
\hline Curiosity (trait) * Sugar & 0.03 & $-0.03,0.09$ & 0.87 & 0.387 \\
\hline Curiosity (trait) * Fruit and Vegetables & 0.00 & $-0.00,0.00$ & 0.20 & 0.842 \\
\hline Observations & \multicolumn{4}{|l|}{170} \\
\hline $\mathrm{R}^{2} / \mathrm{R}^{2}$ adjusted & \multicolumn{4}{|c|}{$0.211 / 0.146$} \\
\hline
\end{tabular}

746

Table S5. Full model predicting daily anxiety levels

\begin{tabular}{lllll}
\hline & \multicolumn{2}{l}{ Daily anxiety } & (mean) & \\
Predictors & Estimates & $95 \% \mathrm{Cl}$ & Statistic & $p$-value \\
\hline (Intercept) & -2.43 & $-11.96,7.09$ & -0.50 & 0.615 \\
Curiosity (trait) & 1.09 & $-1.82,4.00$ & 0.74 & 0.461 \\
Carbohydrates & 0.05 & $-0.07,0.16$ & 0.80 & 0.426 \\
Fat & 0.00 & $-0.13,0.13$ & 0.03 & 0.980 \\
Sugar & 0.25 & $0.07,0.43$ & 2.69 & $\mathbf{0 . 0 0 8}$ \\
Fruit and Vegetables & -0.00 & $-0.01,0.00$ & -1.39 & 0.167 \\
Age & -0.00 & $-0.01,0.01$ & -0.74 & 0.459 \\
Gender & -0.11 & $-0.21,0.00$ & -1.97 & 0.050 \\
Residency (GER, AT) & 0.02 & $-0.09,0.12$ & 0.29 & 0.768 \\
STAI (trait) & 0.02 & $0.01,0.03$ & 3.65 & $<0.001$ \\
Loneliness & 0.00 & $-0.00,0.01$ & 1.10 & 0.275 \\
Curiosity (trait) * Carbohydrates & -0.02 & $-0.05,0.02$ & -0.87 & 0.383 \\
Curiosity (trait) * Fat & 0.00 & $-0.04,0.04$ & 0.05 & 0.958 \\
Curiosity (trait) * Sugar & -0.08 & $-0.13,-0.02$ & -2.71 & $\mathbf{0 . 0 0 7}$ \\
Curiosity (trait) * Fruit and Vegetables & 0.00 & $-0.00,0.00$ & 1.09 & 0.278 \\
\hline Observations & 170 & & & \\
$\mathrm{R}^{2} / \mathrm{R}^{2}$ adjusted & $0.302 / 0.239$ & & &
\end{tabular}

\section{Methods}

Table and plots were created using "gtsummary" ${ }^{1}$, "sjPlot" ${ }^{2}$ and "ggstatsplot" 3. 


\section{COVID-19 impact}

763 We assessed the impact COVID-19 had on participants' lives by asking them to rate how well they complied with the rules, their current work situation (e.g. home-office) and whether they or others they knew contracted the virus:

766

- Work situation: "Arbeiten Sie zur Zeit im Homeoffice bzw. arbeiten/studieren/lernen Sie von zu Hause aus?" ["Do you currently work from home, e.g., work / study / learn from home?”] (answers: $1=Y e s, 2=N o, I$ go to the office, 3=No, I am not working at the moment, 4=No, I have lost my job due

\section{Work situation during COVID-19 lockdown}

Figure S2. Work situation. The majority of participants were working from home.

- Compliance to COVID-19 restrictions, setup by the Government: "Wie streng befolgen Sie die von der Regierung beschlossenen Regeln und Empfehlungen bezüglich der Einschränkung sozialer Kontakte?" ["How strictly do you follow the rules and recommendations adopted by the government regarding the restriction of social contacts?" (answer: $0=$ not at all, $100=$ very strict"]

- Experience with virus (direct, indirect): (1) “Gibt es in Ihrem näheren persönlichen Umfeld eine an Covid-19 erkrankte Person?" ["Is there someone in your immediate personal environment who has

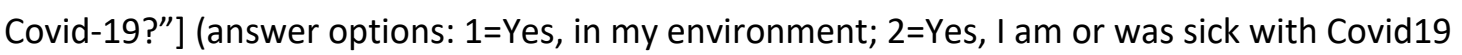
myself; 3=No); (2) "Kümmern oder kümmerten Sie sich um eine an Covid-19 erkrankte Person?" ["Do you take care of a person suffering from Covid-19?"] (answer options: $1=Y e s$, currently; $2=Y e s$, in the past; $3=$ No) 
Table S6. COVID-19 impact, split by country

\begin{tabular}{lllll} 
& Overall, N =183 & Austria, N=54 & Germany, N=129 & $\boldsymbol{P}^{2}$ \\
\hline Follows Covid-19 restrictions & $82.33(19.71)$ & $84.07(15.15)$ & $81.60(21.34)$ & $>0.9$ \\
\hline Covid-19 infection - self & $2 / 183(1.1 \%)$ & $2 / 54(3.7 \%)$ & $0 / 129(0 \%)$ & 0.086 \\
\hline Covid-19 infection - social network & $41 / 183(22 \%)$ & $12 / 54(22 \%)$ & $29 / 129(22 \%)$ & $>0.9$ \\
\hline Covid-19 patient caretaker & & & & 0.8 \\
\hline$-\quad$ Yes, currently & $2 / 183(1.1 \%)$ & $1 / 54(1.9 \%)$ & $1 / 129(0.8 \%)$ & \\
\hline$-\quad$ Yes, previously & $3 / 183(1.6 \%)$ & $1 / 54(1.9 \%)$ & $2 / 129(1.6 \%)$ & \\
\hline$-\quad$ No & $178 / 183(97 \%)$ & $52 / 54(96 \%)$ & $126 / 129(98 \%)$ & \\
\hline
\end{tabular}

788

789

790

791

792

793

794

795

796

797

798

799

800

801

802

803

804

805

806

807

808

809

810

811

812

813

814

815

816

817

${ }^{1}$ Mean (SD); $n / N(\%)$

${ }^{2}$ Wilcoxon rank sum test; Fisher's exact test; Pearson's Chi-squared test

There were no statistical differences between the Austrian and German sample concerning impact of COVID-19.

\section{Information-seeking motivation}

Four questions assessing how willing individuals are to seek information regarding positive and negative information for themselves and about others in current times. For all questions, participants are asked to indicate their motivation using a slider from I am definitely not motivated to look for information (0) to I am highly motivated to look for information (100) [German: Ich bin gar nicht motiviert nach Informationen zu suchen (0) -- Ich bin sehr motiviert nach Informationen zu suchen (100)]. See below.

Wie viele Informationen suchen Sie in AKTUELLEN Zeiten (z.B. im Internet, durch Lesen, Fernsehen, Fragen an Freunde/Familie/etc.). [How much information do you look for in CURRENT times (e.g. on the Internet, by reading, watching TV, asking friends / family / etc.).]

1. Wie sehr sind Sie gewillt, nach Informationen zu suchen, wenn diese Informationen wahrscheinlich POSITIV sind? (also gute Nachrichten) [How motivated are you to seek information, when that information is likely positive? (i.e. good news)]

2. Wie sehr sind Sie gewillt, nach Informationen zu suchen, wenn diese Informationen wahrscheinlich NEGATIV sind? (also schlechte Nachrichten) [How motivated are you to seek information, when that information is likely negative? (i.e. bad news)]

3. Wie sehr sind Sie gewillt, nach Informationen zu suchen, wenn diese Informationen über Andere wahrscheinlich POSITIV sind? (also gute Nachrichten) [How motivated are you to seek information, when that information about others is likely positive? (i.e. good news)]

4. Wie sehr sind Sie gewillt, nach Informationen zu suchen, wenn diese Informationen über Andere wahrscheinlich NEGATIV sind? (also schlechte Nachrichten) [How motivated are you to seek information, when that information about others is likely negative? (i.e. bad news)] 
818

819

820

821

822

823

824

825

826

\section{References}

1. Sjoberg DD, Whiting K, Curry M, Lavery JA, Larmarange J. (2021). Reproducible summary tables with the gtsummary package. The $R$ Journal, 13:570-80. https://doi.org/10.32614/RJ-2021-053.

2. Lüdecke D (2021). sjPlot: Data Visualization for Statistics in SocialScience. R package version 2.8.8, https://CRAN.R-project.org/package=sjPlot

3. Patil, I. (2021). Visualizations with statistical details: The 'ggstatsplot' approach. Journal of Open Source Software, 6(61), 3167, doi:10.21105/joss.03167 